\title{
Family Physician Support for a Family With a Mentally Ill Member
}

\section{J. LeBron McBride, PhD, MPH}

Floyd Medical Center Family Medicine Residency, Rome, Georgia
Conflicts of interest: author reports none.

\section{CORRESPONDING AUTHOR}

J. LeBron McBride, PhD, MPH Floyd Medical Center Family Medicine Residency

Suite 201, 304 Shorter Ave

Rome, GA 30165

lmcbride@floyd.org

\begin{abstract}
Mentally ill family members can have a formidable impact on the families in which they reside. Family physicians can intervene in powerful ways when they are sensitive to those who are mentally ill and their families and can provide much needed compassionate support.
\end{abstract}

Ann Fam Med 2016;14:460-462. doi: 10.1370/afm.1969.

$\mathrm{F}$ amily physicians are on the front lines of mental health treatment. ${ }^{1,2}$ Although there are ongoing debates about the role primary care physicians have in the treatment of those with severe mental illmess, ${ }^{3}$ patients who would never go to a counselor or psychiatrist may trust their family physician with their mental health problems.

Treating mental illness extends beyond the individual patient, however. Family physicians are also important in the care of families that have a member who is mentally ill. Long ago family medicine called for a family approach to health care; the complex interactions in families with mentally ill members, in particular, require a family systems orientation.

I have worked in various settings, including in an outpatient counseling center, as a member of a dual-diagnosis inpatient team, in pastoral care as a member of the clergy, and for more than 20 years as a behavioral scientist in family medicine residency programs. My training in family systems, as well as my clinical experience, has given me great respect for the profound impact of mental illness on a patient and how it affects the entire family system. For instance, a desperate patient who came in with severe anxiety and panic attacks assured me that his was a very good marriage $e_{\text {h }}$ however, when I invited his wife to the next session, she told me she planned to end the marriage. The panic attacks were symptomatic of the problems in the relationship and the wife's impending action, which the patient had not consciously acknowledged. Mental problems do not always result from family dynamics, but their impact does not exist in isolation. I have worked with families who have a mentally ill child and witnessed the agony of good parents who have done all they can, yet their child continues to suffer and, therefore, so do they.

\section{AN OVERVIEW}

The Patient Protection and Affordable Care Act and the patient-centered medical home are designed to increase and enhance collaborative approaches for mental health, and the role and support from a family physician are fundamental in these processes. ${ }^{4}$

Just as severe physical illness often devastates the family, so does severe mental illness, most often with fewer avenues of assistance. Some disorders are more amenable to treatment (eg, some depressions and anxieties), and some are more difficult to treat (eg, schizophrenia); some have acute and recurrent episodes (eg, mania in bipolar spectrum disorders), and some require chronic management (eg, chronic posttraumatic stress disorder). Even though the family physician is not managing severe mental 
illness, he or she may manage the physical care of the patient and family members and play a major role in their psychological support.

Although many issues addressed by mental health treatments can be difficult and messy, it is important not to avoid such patients and their families or stigmatize them, doing so results in poorer or even no care. ${ }^{5}$ For example, one very depressed, diabetic patient was losing his place to live, had a relationship break up, and had lost his job. His physician and I had to treat his depression and assess his suicidal thoughts, while helping him manage his conflicts with a parent and find temporary shelter with the Salvation Army.

\section{KEY CONCEPTS}

\section{Isolation Shuts Down and Confuses}

The stigma associated with mental illness may cause the family to fear repercussions or shaming from others in their social or community network. ${ }^{6}$ The family may isolate themselves to protect the ill member or to protect the family reputation. One woman was referred for depression; she had withdrawn from social activities because she was ashamed of an adult child's mental illness and worried that her "perfect" family was in danger of losing its reputation, thus marring her deceased husband's good name. In other cases, the ill family member may be so unpredictable that family members stop having friends over to their home. Having a physician with whom families can discuss issues and at least vent their difficulties can relieve their stress. The family physician can listen to the family members' stories, ask appropriate questions, and offer hope. In the context of a narrative framework and a caring environment, families can often begin to see options or find ways to cope. ${ }^{7.8}$

At times it will be more effective to see additional family members at a visit. Family visits may be a opportunity to share information about resources, such as The National Alliance on Mental Illness and its local meetings. Involvement with others begins to move the family away from being alone with their burdens.

\section{The Double Whammy: Mental and Physical Problems}

Physical and mental health illnesses can appear together, giving the family a twofold setback; a family that might cope adequately with a mental or physical illness may be overwhelmed when both are present. Severe mental illness increases physical morbidity and mortality. Some factors can be modified by positive lifestyle choices, which can also improve mental health. ${ }^{9,10}$ The family physician's contribution to health education, anticipatory guidance, and preparation for crises, as well as making sense of the illness, can help make functioning, or even survival, seem possible." The physician's help with problem solving and crisis management can bring calmness when the storms erupt. When a mentally ill family member begins to improve, family stress is lessened.

Family members of mentally ill patients are themselves susceptible to physical illness, so maintaining awareness and acknowledging their stressors are paramount. ${ }^{12}$ Much as families with members who are physically ill have been described as "hidden patients," so it is for families where mental illness occurs. Caregivers are at higher risk themselves, not only for physical illness but also for poorer mental health. ${ }^{11(327)}$ Families can inhabit a chaotic world of loss and limited support as they deal with the unpredictable demands of the mentally ill member and the associated stigma and shame. With support and guidance, however, families can play an important role in the life and recovery of their mentally ill member. ${ }^{13}$ Physicians who offer the opportunity for the family to express feelings, as well as give them support, encouragement, and hope about their ability to cope, have been found to be most helpful. ${ }^{14}$

\section{The Legal System Is Not Always Sensitive and Helpful}

It is well known that prisons are crowded with patients who are mentally ill..$^{15}$ Often these institutions are too overwhelmed to provide proper (if any) mental health treatment. The family may not report violent or abusive behavior in an attempt to keep their family member out of the justice system or to avoid any repercussions for someone already in it. Although most persons with mental illness are not violent, in some instances a family may have no choice but to call on the legal system for protection. A trusted family physician can help the family feel more comfortable in exploring this option or in speaking to a psychiatrist or an attorney.

Fortunately, mental health courts (MHCs) are options in many jurisdictions. These courts involve teams of professionals trained in the justice system and in mental health care; the teams can offer a better understanding of those mentally ill persons who become legally entangled. MHCs offer monitoring, treatment, and community service in addition to a problem-solving approach in lieu of incarceration. Research supports that mentally ill persons who participate in MHCs are less likely to reoffend. ${ }^{16}$ Family physicians may be able to help refer appropriate persons to these courts.

\section{Illness Can Become the Family Identity}

The illness identity of a mentally ill person has been addressed in the medical literature, ${ }^{17}$ and it is helpful to expand this concept to the family, as some families can 
get so tangled up in the mental illness that their identity does not extend beyond the illness. A physician can help the family see its strengths and resources, as well as acknowledge its resiliency. By affirming the family's coping style, the family can start moving from a pathological identity to a perspective of strength.

\section{Home May No Longer be a Refuge}

Because resources for mental health care often are not easily accessible, family members may feel abandoned by society and left with few options, resulting in defensiveness and anger at institutions, their community, and even each other.

With a limited ability to help their mentally ill family member, the family home risks becoming a place of sadness, intrusion, or conflict rather than a sanctuary. Some patients with mental illnesses violate personal boundaries and are continually annoying or disturbing. Some family members become overinvolved, whereas others distance themselves. Knowing how to access available resources may be beyond the reach of those who are financially and educationally limited. A physician who can advocate for the family and help them find respite can do much to increase the family's ability to cope and facilitate positive interactions among its members.

\section{FINAL THOUGHTS}

Although not all mental illness is intensely disruptive for the family, mental illness always has its impact. A family physician can be a catalyst for eventually getting the family to a counselor, to a psychiatrist, or into community support. Never underestimate the power of a calm and compassionate family physician upon a family struggling with mental illness. It may be the healing engagement of the family physician that becomes the family's lifeline to find inner strengths and external avenues to survive.

To read or post commentaries in response to this article, see it online at http://www.annfammed.org/content/14/5/460.

Key words: behavioral medicine; mental health; psychosocial issues in healthcare and primary care; patient-centered medical care; medical family therapy
Submitted March 10, 2016; submitted, revised, May 23, 2016; accepted June 20, 2016.

\section{References}

1. Oyama O, Burg MA, Fraser K, Kosch SG. Mental health treatment by family physicians: current practices and preferences. Fam Med. 2012;44(10):704-711.

2. Kiraly B, Gunning K, Leiser J. Primary care issues in patients with mental illness. Am Fam Physician. 2008;78(3):355-362.

3. Morden NE, Mistler LA, Weeks WB, Bartels SJ. Health care for patients with serious mental illness: family medicine's role. J Am Board Fam Med. 2009;22(2):187-195.

4. Raney LE. Integrating primary care and behavioral health: the role of the psychiatrist in the collaborative care model. Am J Psychiatry. 2015;172(8):721-728.

5. Mittal D, Ounpraseuth ST, Reaves $C$, et al. Providers' personal and professional contact with persons with mental illness: relationship to clinical expectations. Psychiatr Serv. 2016;67(1):55-61.

6. Larson JE, Corrigan P. The stigma of families with mental illness. Acad Psychiatry. 2008;32(2):87-91.

7. Shapiro J, Ross V. Applications of narrative theory and therapy to the practice of family medicine. Fam Med. 2002;34(2):96-100.

8. Charon R. The patient-physician relationship. Narrative medicine: a model for empathy, reflection, profession, and trust. JAMA. 2001; 286(15):1897-1902.

9. Lefley HP. Family burden and family stigma in major mental illness. Am Psy. 1989:44.

10. DE Hert M, Correll CU, Bobes J, et al. Physical illness in patients with severe mental disorders. I. Prevalence, impact of medications and disparities in health care. World Psychiatry. 2011;10(1):52-77.

11. Lester $\mathrm{H}$, Tritter JQ, Sorohan $\mathrm{H}$. Managing crisis: the role of primary care for people with serious mental illness. Fam Med. 2004;36(1): 28-34.

12. Shah AJ, Wadoo O, Latoo J. Psychological distress in carers of people with mental disorders. Brit J Med Pract. 2010;3(3):a327.

13. Aldersey HM, Whitley R. Family influence in recovery from severe mental illness. Community Ment Health J. 2015;51(4):467-476.

14. Shor R, Birnbaum M. Meeting unmet needs of families of persons with mental illness: evaluation of a family peer support group. Community Ment Health J. 2012;48(4):482-488.

15. Prins SJ. Prevalence of mental illness in US state prisons: a systematic review. Psychiatr Serv. 2014;65(7):862-872.

16. Mental Health Courts. A Primer of Policymakers and Practitioners. A Report Prepared by the Council of State Government Justice Center for the Bureau of Justice Assistance. NY, NY: US Department of Justice; 2008.

17. Yanos PT, Roe D, Lysaker PH. The impact of illness identity on recovery from severe mental illness. Am J Psychiatr Rehabil. 2010; 13(2):73-93. 